\title{
Research on Application of Grey Relevance Theory in teaching evaluation
}

\author{
Hongfu $\mathrm{Ai}^{1, \mathrm{a}}{ }^{,}, \mathrm{He} \operatorname{Pan}^{1, \mathrm{~b}}$ \\ ${ }^{1}$ Jilin Agricultural University, Changchun, Jilin, 130117, China

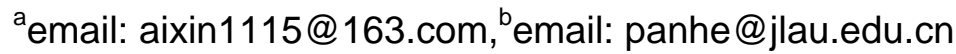

Keywords: Grey system; Grey correlation; Teaching evaluation

\begin{abstract}
The purpose of teaching evaluation is to improve the quality of teaching. The evaluation method of teaching is numerous, and has achieved good results. Due to the particularity of the curriculum, the teaching evaluation of different courses should be different. In this paper, the evaluation model is established based on grey correlation theory, and the course of SPSS statistical analysis is evaluated, and the evaluation index and model are established. According to the experimental results, the course's setting, teaching process and evaluation model were analyzed.
\end{abstract}

\section{Introduction}

Teaching evaluation is an important part of the teaching work in Colleges and universities. Most of the teaching evaluation is aimed at teachers, through the evaluation of different teachers to improve the teaching methods and improve the quality of teaching [1]. This research starts from the course itself, and carries on the depth excavation analysis through the data of the teaching accumulation. Research on teaching methods and teaching strategies is suitable for the course of "statistical analysis of SPSS". The evaluation results are more pertinent, which makes the evaluation result more objective, scientific and reasonable. In this paper, referring to the relevant literature and mathematical model, based on the gray related theory, to assess the "SPSS statistical analysis" teaching quality evaluation model.

Grey theory was proposed by Professor Ju-long Deng. It is a branch of statistics, and the grey system theory has been widely used in the fields of agriculture, economy, and management and so on, and has achieved good results. Applications in the field of education have become a hot topic in recent years. Grey relation is an important part of grey system, which is used to describe the correlation degree between objects. Under the background of big data, data mining and analysis of the teaching itself, found that the value of the hidden behind the data [2]. The gray correlation theory will have great application prospects. At the same time, the grey relational theory belongs to the category of geometric processing, which is widely used in the field of application.

Correlation analysis is a common method of statistical analysis, and the application of grey relational analysis method is more ideal for the practical problems [3]. The method used in this paper takes into account the characteristics of the data object itself, and it is more sensitive to the data analysis, which reflects the role of the data in the analysis [4]. Thus further weakening the impact of the more distant data, more accurately reflects the degree of correlation between the data.

\section{Algorithm description}

\section{Definition of grey sequence}

In order to more clearly describe the grey sequence, the concept of whiteness is given first.

If the original data sequence is set to $\mathrm{S}, \mathrm{S}=\left\{s_{1_{1} s_{2_{n}}, s} s_{\mathrm{m}_{2}}\right\}$, and set the $\mathrm{w}_{\mathrm{i}}=\frac{1}{g_{\mathrm{i}}}=\log _{2}(i)$ for the $\mathrm{S}$ sequence in the first i elements $s_{\tilde{i}_{2}}$ the whiteness, is whitening series:

Where $g_{i}$ is the

$$
W S=\{W, S\}=\left\{\left(w_{1}, s_{1}\right\rangle,\left\langle w_{2}, s_{2}\right\rangle, \ldots\left(w_{n}, s_{n}\right)\right\}
$$

$$
\mathrm{g}_{\mathrm{i}}=\frac{1}{\log _{2}(\mathrm{i})}(i=1,2, \ldots, n)
$$


Set gray to $\mathrm{G}, \mathrm{G}=\left\{g_{1}, g_{2,}, g_{\mathrm{n}}\right\}$, the corresponding data sequence of the gray sequence:

$$
\mathrm{GS}=\{G, S\}=\left\{\left\langle g_{1}, s_{1}\right\rangle,\left(g_{2}, s_{2}\right\rangle_{, \ldots .}\left(g_{n}, s_{n}\right)\right\}
$$

Based on the above basic concept description can be calculated by the gray sequence of mathematical expectations, gray variance, gray covariance and other important digital eigenvalues, the final calculation of the gray correlation coefficient.

\section{Calculation of grey correlation coefficient}

Original set of binary sequences $\mathrm{S}=\left(\mathrm{S}_{1_{1}} \mathrm{~S}_{2}\right)=\left\{\left(\mathrm{s}_{11_{1}} \mathrm{~s}_{12}\right),\left(\mathrm{s}_{21_{1}} \mathrm{~s}_{22}\right), \ldots,\left(\mathrm{s}_{n 1_{1}} \mathrm{~s}_{\mathrm{n} 2}\right)\right\}$, their mean were referred to as $\mathrm{GE}\left(\mathrm{S}_{1}\right)$ and $\mathrm{GE}\left(\mathrm{S}_{2}\right)$, two yuan gray sequence corresponding variance can be written as: $\mathrm{GV}\left(\mathrm{S}_{1}\right)$ and $\mathrm{GV}\left(\mathrm{S}_{2}\right)$. According to the algorithm described above, the binary sequences gray correlation coefficient (standard covariance) can be expressed as:

$$
g \rho\left(S_{1}, S_{2}\right)=\frac{\operatorname{GCov}\left(S_{1}, S_{2}\right)}{\sqrt{\operatorname{GV}\left(S_{1}\right) \operatorname{GV}\left(S_{2}\right)}}
$$

The sequence $S_{1}$ and $S_{2}$ correlation coefficient or covariance standards, can be written as $\mathrm{gP}_{12}$.

According to the algorithm described above gray correlation coefficient for the data symbol sequence a $\mathrm{k}$ columns of $\mathrm{S}=\left\{s_{1_{2}} s_{2_{2}} \ldots, s_{k}\right\}$, the ash can be obtained by calculating correlation coefficient matrix is shown below.

$$
G \mathrm{P}=\left[\begin{array}{cccc}
g \rho_{11} & g \rho_{12} & \mathrm{~L} & g \rho_{1 m} \\
g \rho_{21} & g \rho_{22} & \mathrm{~L} & g \rho_{2 m} \\
\mathrm{~L} & \mathrm{~L} & \mathrm{~L} & \mathrm{~L} \\
g \rho_{m 1} & g \rho_{m 2} & \mathrm{~L} & g \rho_{m m}
\end{array}\right]
$$

\section{Gray Correlation Analysis Process}

Grey Relevance Theory has been proven to have a very good application effect. Binding data characteristics and purpose of this study, and according to the principle of gray theory, set to "SPSS statistical analysis" course evaluation process analysis, to the specific processes shown in Figure 1:

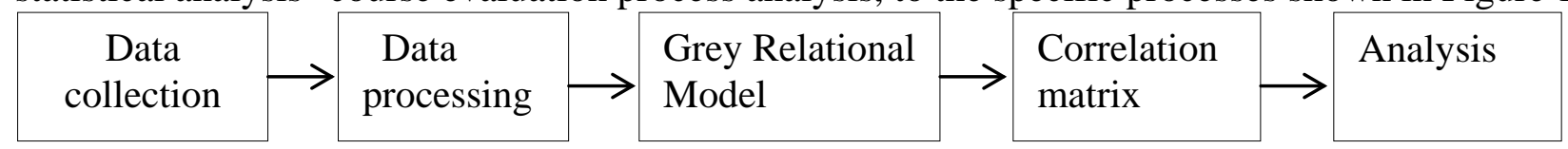

Fig. 1 flow chart of grey relational analysis

Step Grey Relational Analysis Description:

(1) Data collection. Mainly to complete the collection of data, the formation of experimental data through questionnaires and final results data analysis to determine the number of columns.

(2) Data processing. In order to adapt to the gray correlation analysis on the collected data related treatment, including for gender data in this application is set to the proportion of boys; a native data is converted into the proportion of urban students, attendance is converted into a percentage; master's Course the extent and level of computer percentile, and calculate the average of all students; test scores and for total score is the final judge teacher performance, the same percentile of the average of all students. At the same time the data processing dimensionless difference (normalized).

(3) Grey relational model. The grey correlation model is used to simulate the data after processing.

(4) Incidence matrix. The final correlation matrix is obtained through the correlation model. The correlation between different variables can be reflected by the matrix.

(5) The results of analysis. In the correlation analysis, it is very important to find out the correlation degree of each index and the effective use of the relationship matrix. This step is mainly related to the correlation matrix of the strength of the strong and positive correlation, negative correlation analysis. 


\section{Simulations}

\section{Basic data collection}

"SPSS statistical analysis" is a university opened a new basic computer courses, mainly for non-computer science students. Consider this curriculum with its own characteristics, in order to achieve the best teaching results of the 2014 sample survey of 148 students as the object, setting a questionnaire. It includes five indicators, namely: gender; place of origin; attendance; pre-course mastery; level of computer, data obtained real and effective. The course itself is taught to use a software application, highly operative. For student achievement data lists two indicators, respectively, the experimental test scores and total score. The final data is for the seven indicators, and students from different disciplines involved in the investigation of five classes.

\section{Data processing}

Because the data dimension of each index is different, the original data is processed to eliminate the difference in dimension, so as to achieve a better evaluation and analysis results. The stage of pre master degree course, mainly is refers to the students of professional courses of master; computer level is emphasis on students to excel knowledge and programming knowledge to grasp the situation, these two variables in the questionnaire set percentile [5]. For the results of the experiment and the total score, it is the average value of the final examination results of the students.

The research data used in the final form cost study are shown in table 1.

Table 1 Experimental data

\begin{tabular}{|c|l|l|c|l|l|c|c|}
\hline class & $\begin{array}{l}\text { gender ratio } \\
\text { (the } \\
\text { percentage } \\
\text { of boys) }\end{array}$ & $\begin{array}{l}\text { Birthplace } \\
\text { (percentage } \\
\text { town } \\
\text { Birthplace) }\end{array}$ & $\begin{array}{l}\text { attend } \\
\text { ance } \\
(\%)\end{array}$ & $\begin{array}{l}\text { course } \\
\text { master } \\
\text { degree }\end{array}$ & $\begin{array}{l}\text { compu } \\
\text { ter } \\
\text { skills }\end{array}$ & $\begin{array}{c}\text { test } \\
\text { scores }\end{array}$ & $\begin{array}{l}\text { total } \\
\text { scores }\end{array}$ \\
\hline 1 & 52 & 38 & 97 & 85 & 87 & 88 & 81 \\
\hline 2 & 43 & 46 & 93 & 86 & 76 & 88 & 82 \\
\hline 3 & 49 & 39 & 98 & 90 & 82 & 84 & 79 \\
\hline 4 & 54 & 48 & 99 & 87 & 74 & 92 & 84 \\
\hline 5 & 62 & 44 & 96 & 84 & 85 & 91 & 86 \\
\hline
\end{tabular}

\section{Experimental Results}

In this study, the most important is through gray correlation algorithm (equation (1) - Equation (4)) to obtain a correlation matrix gray, gray correlation matrix finally obtained as follows:

$$
r=\left[\begin{array}{rrrrrrr}
1.00 & -0.12 & 0.36 & 0.78 & 0.97 & 0.96 & 0.84 \\
-0.12 & 1.00 & -0.37 & 0.58 & 0.52 & 0.31 & -0.75 \\
0.36 & -0.37 & 1.00 & 0.68 & 0.86 & 0.89 & 0.92 \\
0.78 & 0.58 & 0.68 & 1.00 & 0.74 & 0.88 & 0.78 \\
0.97 & 0.52 & 0.86 & 0.74 & 1.00 & 0.91 & 0.87 \\
0.96 & 0.31 & 0.89 & 0.88 & 0.91 & 1.00 & 0.83 \\
0.84 & -0.75 & 0.92 & 0.78 & 0.87 & 0.83 & 1.00
\end{array}\right]
$$

The above shows that the correlation coefficient matrix between the indicators obtained through the gray correlation algorithm, through the matrix can be found that the correlation between the indicators.

\section{Results analysis}

Through the correlation coefficient matrix, we can see that the male gender ratio and the experimental result are highly correlated, and the class of the gender ratio is high, and the experimental results are high. But their total score did not too big difference, show some students although hands-on ability is not high, but good at memorization, so the difference in total scores of smaller. Can also see, a high proportion of native place of student test scores higher, pre course of master degree, with its level of computer has a direct impact on the total score of the students. In summary of the correlation analysis, we can improve the curriculum and teaching of the curriculum (such as different students can be divided into different levels of teaching). According to its own 
characteristics, it should be more experimental results reflect the actual effect of teaching, it is recommended to increase the proportion of experimental results in the future, and the ultimate goal is to improve the teaching effect. Making the computer basic course set more reasonable.

\section{Conclusions}

The study on Application of grey system theory in the category of the association analysis, compared with the grey correlation and classical correlation analysis, use the advantages of grey relational analysis of a college computer common course - the SPSS statistical analysis in teaching evaluation and analysis [6]. Through the collection of data in teaching, set the corresponding evaluation index, through the gray correlation algorithm, get the correlation degree between the indicators. Through the analysis of the results of the curriculum and teaching methods and examination model put forward scientific suggestions, and the results are applied to the computer based teaching, improve the quality of teaching.

\section{Acknowledgement}

In this paper, the research was sponsored by the Education Department of Jilin province " Twelve five " planning scientific research: (Project No. Ji Zi [2015] No. 183) and 2015 Institute of higher education and scientific research of Jilin Province: (Project No. JGJX2015D34).

\section{References}

[1] Deng Ju-long. Gray theoretical basis[M]. Huazhong University of Science and Technology Press.2002.2.

[2] Yang Hong-juan,Xia Ying,Wang Qing-yun.The Effect Evaluation of the Classroom Teaching of Universities Based on Gray Correlation[J].Value Engineering, 2015(01)245-247.

[3] ZOU Ying,GUO Shi-ping.Advanced Mathematics Quality Evaluation Based on Grey Correlation Analysis[J].Journal of Hefei Teachers College. 2009(06)15-20.

[4] RAN Yanhui,TANG Wanmei.Research on Teaching Evaluation Based on Cloud-Grey Relational Analysis[J].Journal of Chongqing Normal University(Natural Science). 2015(1)142-145.

[5] MA Hong.Evaluating Teaching Quality Using Gray Trend Relational Analysis[J].Journal of Wuhan University of Technology. 2010(15) 181-184.

[6] Li Zhi-jun,Zhang Lei,Chen Mian-yun.etal.Research and Application of Data Mining Method Based on Gray Trend Relational Analysis[J].Proceeding of PACIIA.2008(2):98-101 